\title{
The Obstacles Against the Success of 'Suggestopedia' as a Method for ELT (English Language Teaching) in Global Classrooms
}

\section{Tamer Osman}

Department of English Studies, School of Foreign Languages, Zhengzhou University, Zhengzhou, China

Email address:

eternelutopia@gmail.com

To cite this article:

Tamer Osman. The Obstacles Against the Success of 'Suggestopedia' as a Method for ELT (English Language Teaching) in Global Classrooms. American Journal of Applied Psychology. Vol. 6, No. 5, 2017, pp. 98-105. doi: 10.11648/j.ajap.20170605.13

Received: November 27, 2016; Accepted: January 20, 2017; Published: October 19, 2017

\begin{abstract}
This research tackles the factors that represent obstacles against the success of 'Suggesopedia' as a method that could prove its inefficiency in ELT (English Language Teaching) in global classrooms. It analyzes these obstacles from various perspectives and reveals the indicators of this inefficiency.
\end{abstract}

Keywords: Suggestopedia, ELT (English Language Teaching), Cognitive Psychology Metalinguistic Factors, Metacognition, Mnemonic Device, Behaviorism, Constructivism

\section{Introduction}

Suggestopedia is a portmanteau of 'suggest' and 'pedagogy. It is a teaching method that was basically developed by the Bulgarian psychotherapist Georgi Lozanov in the 1970s to teach foreign languages. It is a set of learning recommendations derived from Suggestology, which Lozanov describes as "a science ... concerned with systematic study of the irrational and/or non-conscience influences" that human beings are constantly responding to. This method is also grounded upon insights from yoga and the Soviet psychology. It emphasizes the 'desuggestive learning, so recently, it has been called 'desuggestopedia' as well. Lozanov mentions on his website, Suggestology and Suggestopedy, that 'suggestopedia is a system for liberation,' the liberation from the 'preliminary negative concept regarding the difficulties in the process of learning' that are created by the society or any external elements. Desuggestopedia engulfs liberation as Lozanov describes 'desuggestive learning' as 'free, without a mildest pressure, liberation of previously suggested programs to restrict intelligence and spontaneous acquisition of knowledge, skills and habits.'The implementation of this method is not executed by anatomizing the conscious level of human mind only but the subconscious level as well, the mind's reserves. Lozarnov believes that since Suggestopedia, as a teaching method, deals with the human brain with all its unlimited capacities, so the human brain can assimilate much information using this method rather than other teaching methods. Schiffler thinks that the intended purpose of Suggestopedia was to enhance learning by lowering the affective filter of learners.

Suggestopedia was officially observed by a twenty-fiveexpert commission from the UNESCO in 1978. It was evaluated as a superior teaching method and was recommended for being adpoted by the educational institutions on the international level.. As a result, Lozanov was detained under house arrest for the period $1980-1989$ until the political stance was changed in Bulgaria.

\section{Demographic Factors}

\subsection{Age Categories}

The issue of age was first addressed with the critical period hypothesis. The precise version of this hypothesis shows that there is a designated point of termination age at about 12 , after which learners lose the ability to fully learn a language.

However, the exact age marking the end of the critical period is debated, and ranges from age 6 to 13, with many 
arguing that it is almost in the beginning of adolescence. This rigid version has since been rejected for second-language acquisition, as some adult learners have proved their linguistic capabilities of attaining linguistic fluency approaching native-like levels in relation to pronunciation and skills. Nevertheless, some linguists have been arguing that second-language adult learners rarely achieve the native-like fluency that children could acquire regardless of their raid progression in their early stages. This has led to an intuitive conclusion that age is indirectly concerned with other language learning pivotal factors.

Is the usage of Suggesopedia in the ESL /EFL classes accepted by the adult learners as much as the children and adolescent learners? Practically, this educational orientation is difficult to take place in quotidian life if it is applied in the ESL/EFL classes disregarding the cultural differences. For example, some adult learners with some cultural backgrounds could not appreciate this orientation in the classes. This orientation could be interpreted as a waste of time, taking into consideration within these same cultural milieus, the children and the adolescents could assimilate it withe acceptance of their caregivers.

\subsection{Geographical Location}

If the question of the age category plays a role in the assimilation or the rejection of Suggestopedia, the geographical location of the ESL /EFL classes is another central factor that could encourage and discourage learners from accepting this orientation. Undeniably, the learners dwelling the urban regions are unlike those learners dwelling the rural regions within one country. The learners in the urban regions would foster modernized and sophisticated styles and orientations more that the learners in the rural regions. Therefore, Suggestopedia would be anticipated to be assimilated by the learners in the urban regions rather than those in the rural regions, taking into consideration one more time the cultural backgrounds.

\section{Sociocultural Factors}

Scholars have referred to the fashion culture demonstrates itself in the ESL /EFL classes as the hidden curriculum. This means that ESL /EFL teachers or instructors can then employ this knowledge of learners' background, interests, and experiences to prepare culturally relevant pedagogical plans. Designing culturally relevant pedagogical plans

can be considered as an intentionally instructional practice and theoretical pattern that develops the academic progression of the learners, ground the cultural identity of the learners, and assist the learners in creating critical perspectives that are necessitated to overcome inequities in educational institutions and communities.

Hence, Suggesopedia attempts to conflict with the cultural identities of the learners and the customs and the traditions of the societies and the communities.

English and the methodology of teaching it as a lingua franca where Suggestopedia is one among these methodologies strives to find its way in the labyrinth of the cultural identities and traditions on the global level.

Establishing global forums and conferences in an attempt to address all the miscomprehended concepts related to the English teaching methodologies where Suggestopedia is one of these methodologies can be somehow semi-persuasive solution. ESL/EFL experts could open sessions in different regions of the world where the discussions and arguments could generate rectification of all the problematic issues around Suggestopedia or any other teaching methodologies.

Dr. Milton Bennett, developed the Developmental Model of Intercultural Sensitivity (DMIS), states that the cultural differences can not be ignored by the educationalists if the education process is meant to make remarkable progression. He refers to the problem of ethnocentrism and the proper education process, as it could be one of the impediments of achieving the desirable success of the learners' progression. The questions that will pose itself at this point, 'how can Suggestopedia find its way in the ESL/EFL classes while ethnocentrism is considered?' In fact, the answer to this question is quite complicated. The most important issue that must be drawn attention to is persuasion. Learners must be psychologically persuaded that utilizing Suggestopedia in the ESL /EFL classes can be very utile and that would assist them in rapidly progressing toward to fluency and capability to effectively communicate with the public in the quotidian life without any hesitation and with entire confidence.

Hence, it can be said that the cultural backgrounds of the ELLs (English Language Learners) plays a vital role in the success or the failure of the ESL / EFL classes in some regions of the world. The beliefs and the traditions and habits of diverse learners and the societies and the communities they belong to could impede the flexibility of the

ESL /EFL lesson plans that could be based upon Suggestopedia.

\section{Psychological Factors}

On the account of the brain that is usually attracted to innovativeness, it can be described as actively craving distractions, which will automatically intervenes with learning process. And the function of memory is to impede the encoding of information that is unintended or unnecessary for developmental learning process. That could rank Suggestopedia as an ideal teaching methodology that the brain could positively imbibe. But does the brain strive between the sociocultural factors mastering the faculties of the learners involved in the langauge acquition process and the psychological desire to embrace the communicative methodology, Suggesopedia? Undeniably, the conflict exists in some cultural milieus. The compliance of the brain to accept Suggetopedia is attributed to the characters of the learners themselves. Some learners would adopt Suggestopedia as a method of learning acquisition while ignoring any sociocultural factors that could hamper them. Other learners would yield themselves to the sociocultural factors while their brains endeavor to reject Suggestopedia as 
a method of teaching and learning.

Thus, the psychological harmonization between the brain desire and socicultural factors is an inevitable issue that many learners in some cultural milieus can not handle. But should the ESL /EFL teachers or instructors get involved into raising awareness to their learners in relation to the vitality of their adoption of new teaching methodologies like Suggestopedia? Many learners would repudiate the idea while others could respond by listening to it, but maybe without being totally convinced. That still depends on the societies and the communities where this awareness takes place. Therefore, the instructors/teachers have to get apprised of taking such an action and predict the reaction to it as well. This will lead us to the idea that the instructors/teachers have to accept these two kinds of learners in their classes and which oblige the harmonization among all the learners. Accordingly, the instructors / teachers surrender to the presence of the deficit model who would demonstrate some kind of hostility and skepticism towards adopting any nontraditional teaching methodology like Suggestopedia. It is harsh mission on behalf of the instructors/ teachers to deal with the gap among learners. The model urges that communication should concentrate upon ameliorating the transfer of information from 'experts to non-experts', i.e. here, the two kinds of learners.

(Pease, 1988, p. 9-13; Bailey, 2001, p. 44; Kasikci, 2003, p. 19-20; Kuhnke, 2007, p. 12; Feng, 2009) state that 'In verbal communication, it has emerged that the content of speech has $7 \%$, tone and quality has $38 \%$, and body language has $55 \%$ effect'. Rising out of this data, the argument can be around the importance of the fashion and the behaviors of the interlocutors when delivering a speech or addressing others rather than the topics they tackle. Suggestopedia depends on the body language and movement. So that would prove this data can conform to Suggesopedia and that the latter could always prove its credibility and success as an ELT methodology. Then what about the the brain conflict between the sociocultural factors and its desire of the innovative methodologies and the verbal communication endorsed by its own faculties? This increases the patent conflict of the learners when they handle language acquisition.

The response from the learners can vary from one leaner to another, but it is till the duty of the instructors/ teachers to instigate the learners to positively participate in the classes. The positive attitude of the body language of the instructors/ teachers is the energetic element that would urge learners positively participate in the class activities. Suggesopedia could credibly regulate this relationship, but the other central impediments can still not be disregarded.

\subsection{Mnemonic Device}

Mnemonic, Mnemonic Device, or Memory Device is any learning technique that boosts information retention in the human memory. So Mnemonics target the interpretation of any information into a form that the brain can ameliorate its retention than in its original form. Even the process of merely learning this conversion might already contribute to the transfer of information to long-term memory. Commonly encountered mnemonics are often utilized for itemized and auditory forms, such as short poems, acronyms, or memorable phrases, but mnemonics can be utilized for visual or kinesthetic information.

Ruth O'hara (2007) mentions in Journal of Psychiatric Research that Mnemonics were viewed to be more effective for categories of people striving with weak long-term memory like seniors. Correspondingly, provided that Mnemonics cherish the target of Suggesopedia in the ESL /EFL classes, how far might Suggestopedia succeed in attaining fluency for ESL /EFL seniors?

It is believed that the sociocultural factors would impose themselves in the language acquisition process. That implies that Suggesopedia is relatively proportional when its success is to recorded in this case. Seniors in some global societies and communities do not adequately care about developing their mental or instinctive skills. So how would they engage Mnemonics with Suggesopedia to be able to effortlessly and properly communicate in English, taking into account that sometimes learning English for these seniors is compulsory matter for social reasons and not an optional matter. On the other hand, some cultural heritage in some societies and communities energize the patent capabilities and talents for their seniors, that they would not captivate themselves to the rejection of abandoning any novelties related to triggering brainstorming and mindsets.

\subsection{The Relationship Between Mnemonic Device and English Language Acquisition}

Mnemonic device serve English language learners to augment their language acquisition. For example, it can be employed with false cognates between English and a foreign language of a Latin or Greek origin like French. But it does not prove its efficiency for learners whose mother tongues of non-Latin or non-Greek background, as referring to the false cognates would be meaningless at this point.

Mnemonic device can be utilized with homophones in English vocabulary baggage, as learners would enrich their vocabularies in a short period of time.

But any attempts on behalf of the instructors / teachers to draw comparisons between English and a Latin language like French can be fruitless, as this method would not make any English learners of any cultural background acquire any new and genuine information

\section{Metalinguistic Factors}

Metalinguistic Awareness refers to the ability of not only assigning language as a process, but also as a device. The concept of metalinguistic awareness aims at interpreting the processing and transferring of linguistic knowledge across languages (e.g. code switching as and translation among bilinguals and multilinguals). That is the pretext that could urge us to say that metalinguistics can be viewed as the ability to alertly reflect on the nature of language. Thus, should the tools of metalinguisitic awareness are exploited to enhance 
Suggesopedia in ESL /EFL classes, the following contradictory results will be depicted:

1. If metalinguistic awareness demonstrates that language has a potential greater implications represented in deepening the significance of any linguistic unit, Suggesopedia might penetrate the metalinguistic awareness domain to prompt the brain to manipulate its mental capabilities with the purpose of intensifying the efforts of language acquisition. But would any learner exert the requested efforts to manipulate their mental capabilities to harmonize with a teaching methodology like Suggestopedia? Indubitably, lifestyles and character traits of the learners are the elements that would form the success of the harmonization between metalinguistic awareness and Suggestopedia. Yielding the brain to consciously fostering metalinguistic awareness to use Suggesopedia for leaning purposes necessitates psychological intervention. This intervention necessitates psychological fortification provoking the self-determination, will, persistence of the learners. Therefore, the percentage of success at this point would be entirely anticipated, since psychologically, there are people who are incapable of yielding their traits to any kinds of mental exercises.

2. An awareness that language is wrought as its structures can be altered and corrected in case that these structures are misformed. These phenomenal features could definitely Suggestopedia ESL /EFL classes. But is linking these features with Suggestopedia in in-class Suggestopedia activities sufficient to boost the academic linguistic levels of the learners?As a matter of fact, learners have to ground their fluency efforts on take-home and class group activities in order to achieve comprehensive language acquisition.

\section{Some Kinds of Learners and Their Response to Suggestopedia}

\subsection{Kinesthetic Learners}

Since kinesthetic learners learn through active movements and experiences. Learners are involved in in-class activities such as playing, puppetry, drama, acting and designing That compels the ESL /EFL instructors/ teachers to master their class management. So Suggestopedia creates the fertile environment for the kinesthetic learners. They can positively respond thanks to any activities with Suggestopedia, as it is commensurate with their character nature.

Some effective strategies used to involve unmotivated kinesthetic students during activities where Suggestopedia is adopted:

- Motivating the students by giving attention and reward, avoid punishment. This attitude could be accepted according to the age categories. This can applied with children and teenagers, but this is quite uninfluential with adults, as that may be considered to be an insult to their intelligence at least in some societies and communities.

- Learners should be provided with options to choose among the activities for learning particular concepts. But sometimes, these options are unworthy for the learners' progression and their judgment is usually superficial unless orientated by the instructors/ teachers. In addition to this, some learners in some societies and communities might adopt Suggestopedia, but these learners have never been given the opportunity to learn how to choose what could be useful and inutile for their progression in their academic lives.

- Every learner has to be given equal opportunity to participate in in-class ESL/EFL acclivities. So Suggestopedia could completely help learners achieving this objective. But if the aptitude towards language learning is absent, the instructors /teacher could not motivate their learners at this point, as yielding brain to the acquisition process is quite indispensable.

- Simultaneously, there must be some effective strategies followed by the instructors/ teacher in the ESL/ EFL classes to keep control of the learners while dealing with activities with Suggestopedia:

- Encouraging learners to discard any social shyness while practicing activities necessitating body movement

- Regular monitoring of the learners' response and concentrating upon all of them

- Appropriate and accurate directions have to be given to learners for any activity, so that the learners would not get frustrated, especially if they are seniors.

Among the feeble aspects of the above-mentioned arrangements that can be set for kinethetic learners is the entire concentrations that is necessary for the other kinds of learners. Class management could not be entirely realized. So the ESL/EFL instructors/ teacher could encounter soem dissatisfaction from some learners.

Bearing in mind that Suggestopedia is chiefly grounded upon movements in the classroom. In addition to this, some learners may not gain high percentage of the information as anticipated as a result of the class environment.

\subsection{Visual Learners}

When the visual field of the brain receives new information to recognize and categorize it, the brain itself starts to encode this information with the purpose of validating the learning process. With the amalgamation of the tasks of recognition, categorization and learning; schemas help processing the encoding of new information and relating it to familiar objects that the learners are aware of. The learners can remember visual images much better when they link them to an already -known schema. Scientifically, schemas actually provide visual memory and learning boost. Inasmuch as Suggestopedia banks on using audio-visual means, so visual learners would sense it; nonetheless, some learners in various societies and communities could not handle it. The latter learners' learning process reckons on memorizing information rather than resorting to audio-visual means to acquire information. This reveals that they may envisage some 
difficulties in dealing with Suggestopedia.

\section{Schools of Learning and Suggestopedia}

\subsection{The Relationship Between Suggestopedia and Some Constructivist Theories}

George Kelly, the creator of personal construct theory, is principally concerned with the epistemic role of the observer in interpreting reality. He believes that the fashion people predict to experience the world changes how they percept it and react towards it. People order themselves by ordering their thoughts. Rising out of this concept, he seeks permitting people to explore their own minds while acting as a facilitator of this exploration process of their own meanings, or what can be called"constructs".

Suggestopedia can be treated as a conceptual teaching methodology for ESL /EFL classes according to the therapeutic approach upheld by George Kelly. Can learners foment such an approach? Some learners would sturdily reinforce their language acquisition process by assimilating Suggetopedia. Other learners would not definitely indulge themselves into exerting efforts to pursuit Suggestopedia. The percentages of acceptance and rejection on behalf of the learners to Suggestopedia would depend on the cultural backgrounds and demographic factors. Without any doubt, the ESL /EFL instructors/ teachers may play a vital role in stimulating the learners' brain to gradually assent to Suggestopedia.

Jean Piaget, the creator of genetic epistemology, states that knowledge is not a priori, but knowledge is developing structures through interaction. According to behaviorists, Piaget's theory is ultimately 'falsificationist' since they believe that 'behavior is the motor of evolution'.

Regardless of the behaviorists' view, Piaget's interpretation of knowledge processing serve and support Suggestopedia and instigate language professionals to adhere to the constructivist orientation if they believe in the role of Suggestopedia in ESL/EFL classes or language learning classes. Suggestopedia activities rely on 'interaction' which is the core of Piaget's theories. But if this teaching orientation is fund be effective in regions of the world, there another regions on the world whose preference would be directed into behaviorism as a teaching methodology. So some learners whose residency are temporary or for social or political reasons in another countries could get them perplexed among teaching orientations due to the different cultural and educational orientations. Hence, constructivism and bahviorism are kept on equal levels. Piaget's approach to constructivism was further developed in neo-Piagetian theories of cognitive development and that will be discussed later in the research.

\subsection{The Relationship Between Suggestopedia and Some Behaviorism Theories}

What was important for a behaviorist's analysis of human behavior is not language acquisition so much as the interaction between language and overt behavior. In an essay republished in his 1969 in Contingencies of Reinforcement book, Skinner assumes the view that humans could construct linguistic stimuli that would then acquire control over their behavior in the same fashion that external stimuli could. The probability of such "instructional control" over behavior meant that possibilities s of reinforcement would not always produce the same effects on human behavior as they reliably do in other animals. So could Suggesopedia intervene with the process of the language stimuli to achieve specific ESL /EFL objectives? Should the psychological aptitude and the sociocultural factors are in frustrating conflict with the language stimuli, learners would definitely not be able to achieve the anticipated learning objectives. On the other hand, instructors / teachers can not direct their orientated teaching methodology using Suggestopedia without receiving positive response from their learners who should be yielding their brains to the language stimuli. At this point, constructivism orientation could attain higher percentages than behaviorism orientation in spurring the psychological aptitude and the brain capabilities to target specific ESL/EFL progression.

\section{Metacognition: Its Role with Suggestopedia}

Metacognition is 'cognition about cognition', 'thinking about thinking', or 'knowing about knowing'. It targets knowledge about when and how to utilize specific strategies for the learning process or for problem solving. There are generally two components of metacognition: knowledge about cognition, and regulation of cognition. Astonishingly, metacogition is the inciter which would arouse the learners' curiosity to familiarize themselves about how Suggestopedia as a practical teaching methodology.

Learners must get attracted to Suggesopedia as teaching methodology with the purpose of adopting it, so learners would get involved into successful learning process.

It is the role of the instructors./ teachers to be cognizant of how utilize Suggestopedia in harmony with the sociocultural factors, demographic factors and psychological factors related to the learners and their societies or communities.

If the instructors / teachers have not know how to effectively communicate with learners and convince them with Suggestopedia as a teaching method, metacogntion would not intervene to treat the attitude of the learners that could be represented in some negative attitude like idleness, rebelliousness, rejection and denunciation.

While Dunlosky, J. \& Bjork, R. A. in 'Handbook of Metamemory and Memory' view Metamemory, a type of metacognition, is both the introspective knowledge of one own memory capabilities (and strategies that can aid memory) and the processes involved in memory self-monitoring. This self-awareness of memory has vital implications about how people learn and use memories. When studying, for example, 
learners judge whether they have successfully learned the assigned materials and used their sense, and that is called "Judgments of Learning" which allocates time for studying and comprehension. Suggestopedia could contribute, with its nature and features, to facilitating the processing and the assimilation of knowledge which is mainly acted by Metmemory. Suggesopedia with all its aspects is practical in being adopted psychologically and mentally by learners.

But the most essential language acquisition element that has to exist or is yielded to exist is the inner aptitude, whether it is represented in psychological fortification or brain provocation or both of them.

\section{Metalinguistic Awareness: Catalyst for Suggestopedia}

Metalinguistic Awareness is an ability that processeslanguage. The concept of metalinguistic awareness interprets the processing and transferring of linguistic knowledge across languages. In other words, it represents a code that switches and interprets among bilinguals and multilinguals. Metalinguistics can be classified as the ability to consciously reflect on the nature of language via referring to the following skills:

1. An awareness that language targets the 'nuance' meanings of objects and not just their superficial significance. Suggesopedia activates this role in a positive fashion, but provoking the brain capabilities are very indispensable if the whole process is to considered to gain acceptable amount of information.

2. An awareness that words are dissociable from their referents. ESL/EFL instructors/ teachers would not encounter any difficulties in assigning role-plays and oral presentations via ESL/EFL activities as the significance of the new vocabulary is completely e clarified and explained after eliminating any ambiguity. And here the issue of ambiguity might appear for some learners who are unable to fully take part in activities as a result of the partial awareness of the significance for the chain of words of a textbook unit or a lesson plan vocabularies.

3. An awareness that language has a wrought structures that can be rewritten in other forms or correct in case that there any errors of any kinds. ESL /EFL instructors/ teachers can use this awareness when error-correction can be executed in Suggesopedia activities. But attention must be drawn to those learners who regard error-correction as some kind of social embarrassment in some societies and communities.

The dissatisfying kind of error-correction treatment taken by some ESL /EFL instructors/ teachers could lead some learners to quit the classes or get depressed. Therefore, the treatment should be dealt with carefully. Some learners requires to feel that they are not mistaken, but they desire to make their classmates understand that any error committed by them represents some kind of misunderstanding and usually this misunderstanding is on behalf of the ESL/EFL instructors/ teachers.

\section{Neurolinguistc Factors}

One of neurolinguistics conceptualization is concerned with resorting to electrophysiological techniques to analyze the rapid processing of language in time. The temporal ordering of specific patterns in brain activity may reflect discrete computational processes that the brain undergoes during language processing.

Suggestopedia aid learners to skillfully envision the syntatic and semantic forms of the English language while music is used in its activities or used as background. In fact, it has been proved that background music has rationally positive effects on non-musical tasks, including behavior changes, especially for learners and workers. So if music is highly considered in Suggestopedia activities, the positive amount of language acquisition is undeniably anticipated. Music can affect performance of the doers of cognitive tasks like intense memorization, mental concentration and targetcomprehension. Background music can influence the acquisition process, the learners' triggering memory and the recalling activity. But some kinds of learners in some societies and communities are unable to cope to make music intervene with any educational materials. They might get distracted and the percentage of in-class concentration might decrease. In this case, music neurolinguistically is a factor of impediments towards the proper language learning. ESL/EFL instructors/ teachers have to be considerate of this issue when preparing their lesson plans; otherwise, there might exist some kind of challenging learning circumstances that the learners would definitely and unconsciously affront. On the other hand, spirit of conflict among learners might arise and the instructors/teachers could not master their learners' academic performance and progression.

O'Neill, Susan; Sloboda, John in 'Psychology of Music, Musical ability'. Grove Music Online, Oxford Music Online mention that musical aptitude refers to a person's innate ability to acquire skills and knowledge wit $h$ the presence of musical activity, and may influence the speed at which learning process can occur and the academic level that may be reached.

Study in this area focuses on whether aptitude can be broken into subsets or represented as a single construct, whether aptitude can be measured prior to hefty achievement, whether high aptitude can forebode achievement, the extent to which aptitude is inbred, and the significant questions of aptitude relating to educational principles. Using music in Suggestopedia activities can prompt all these innate capabilities that thrust the language acquisition process. But at the same time, some learners' senses can not perceive music in ESL/EFL activities with positiveness, but as a source of disturbance.

Post, Sean; Schumm, Jeanne Shay (1997) in 'Executive Learning: Successful Strategies for College Reading and Studying Successful Strategies for College Reading and 
Studying' point out that distraction is caused by the lack of the ability to concentrate and find interest in the object of attention; or the fierce intensity, novelty or attractiveness of something other than the object of attention. Distractions are caused via both external sources and internal sources. External distractions include factors such as music, visual triggers, social interactions, text messages, and phone calls.

\section{Result}

\section{Cognitive Development and Language Learning}

\subsection{The Relationship Between Suggestopedia and Cognitive Development and Language Learning Process}

A major question in the study of cognitive development is the extent to which certain abilities are instinctive or acquired. So is language instinctive or acquired? How far does Suggestopedia make success in the triggering the instinctive abilities or the acquisition process? The nativists highlight that certain features are innate to an organism and are determined by its genetic endowment. On the other hand, the empiricists highlight that certain abilities are acquired from the milieus where learners are present. Although clearly both genetic and societal input is needed for learners to acquire any language normally, intricate debate poses itself about how genetic data might guide cognitive development. Steven Pinker views language acquisition takes place as precise information containing universal connotative grammatical rules are born in the genes, whereas Jeffrey Elman and colleagues in Rethinking Innateness believe that Pinker's hypothesis are biologically unrealistic. They defend their argument as genes determine the architecture of a learning system, but the specific "facts" about the functions of grammar can only be acquired by life experiences. Suggestopedia can intervene in what is related to the acquisition part of the language learning process. But the negative part of this process is that Suggesopedia can not handle boosting the innate abilities of the learners if the psychological preparedness for the learning process is not present. Some learners need some external inciters like rewards, concrete necessities, etc... to handle their innate abilities and if these external inciters do not exist in the learners' milieus, Suggesopedia as a teaching methodology would not find space in the brain capabilities of the learners.

\subsection{The Relationship Between Suggestopedia and Cognitive Development and Behaviorism Pedagogy}

Behavioral observations involve the direct witnessing of the behavior actor (e.g., monitoring the learners' positive and negative reactions towards the comprehensibility and incomprehensibility of course materials). Behavioral choices are applied to the desire of the learners of opting one ESL/EFL activity to another.

Here are its aspects that can be considered by the ESL /EFL instructors /teachers:

- Reaction time. The time between the presentation of a stimulus and an appropriate response can indicate differences between two cognitive processes, and can show some indications about their nature. For instance, if the reaction times vary proportionally with the number of elements in a Suggestopedia task, it will be evident that this cognitive process of handling this activity involves serial instead of parallel processing.

So ESL/EFL instructors/ teachers have to cogitate the timing when different kinds of learners whose cognitive processing of the Suggesopedia tasks will vary.

Otherwise, some learners would advance in tasks of the activity more than the other learners. And that will eventually to the partial success of the whole Suggetopedia activity.

- Psychophysical responses. Psychophysical experiments, adopted by cognitive psychology, exploits the decision-making of judgments about some physical property like loudness of sound. Correlation of subjective scales between individuals can show cognitive or sensory biases as compared to actual physical measurements. ESL /EFL instructors/teacher can observe the physical reactions of their learners that emerge out of the psychological states demonstrating the reaction of the learners towards to the course materials and in-class activities. Since Suggestopedia is involved in impelling learners to take part in in-class activities, ESL/EFL instructors/ teachers can monitor the positive and negative indicators of the experiences of the learners like long faces, mumbling, rejection to doing assignments and tasks, and low tone of voices. Furthermore, some learners in some societies and communities are able to concede their reactions as they might boast about their incomprehensibility or incapability. That would urge ESL /EFL instructors / teachers to gently and intelligently treat these issues to assist these learners overcome this obstacle towards to their in-class active participation.

- Eye tracking. This teaching method is used to scrutinize a variety of cognitive processes, most remarkably visual perception and language processing. The fixation point of the eyes is appended to an individual's focus of attention.

Thus, by monitoring eye movements of the learners during a Suggestopedia task, ESL/EFL instructors / teachers can monitor the information that is being processed by learners at a given time. Eye tracking allows instructors/ teachers to discern the cognitive processes on extremely short time scales. Eye movements reflect online decision making during a Suggestopedia task, and learners provide instructors/ teachers with some insight into the fashion in which those decisions may be processed.

If the eyes of the learners depict some rebelliousness towards the classes, ESL/ EFL instructors/ teachers might somehow change the lesson plans or engage these learners in a different activities that could make them re-engage into the class activities.

\section{Conclusion}


The Relationship between Suggestopedia and Competence versus Performance

Chomsky discriminate competence, an idealized learning capacity, from performance, the production of actual utterances. Competence is the ideal interlocutor-auditor's knowledge of their language, and the 'mental reality' responsible for all the 'linguistic' aspects.

Chomsky contends that competence is the ideal language system that enables interlocutors to produce and comprehend an infinite number of sentences in their languages, and to singularize grammatical sentences from ungrammatical sentences. This is unaffected by "grammatically irrelevant conditions" such as speech errors. Esl/EFL instructors can examine the competence of their learners with the purpose of disclosing their patent talents and academic skills. This can be consummated independently from performance, language use, that is assessed its accuracy during Suggestopedia tasks. If ESL/EFL instructors/teachers or assessors are unable to professionally evaluate the competence of their learners and skillfully assess their performance during Suggestopdia tasks, learners would not achieve unobjectionable amount of progress. Sometimes, ESL/EFL instructors/teachers or assessors may fail to adequately evaluate and assess their tasks due to psychological and social harsh circumstances that learners may defy.

Chomsky disputes that he "extracting patterns" from a corpus of observed speech and the describing "speech habits" etc. are the core factors that preclude the development of a theory of actual performance. Suggestopedia activities support learners to deal with speaking activities and which can be monitored by instructors./ teachers or assessors to squarely monitor the academic progression of the learners.

\section{References}

[1] Lozanov, Georgi. Suggestology and Suggestopedy. http://lozanov.hit.bg/ 4/30/2006

[2] Harmer, Jeremy. The Practice of English Language Teaching. 3rd Edition. Person Education Limited, 2001.

[3] Lozanov, Georgi. Suggestopaedia - Desggestive Teaching
Communicative Method on the Level of the Hidden Reserves of the Human Mind. http://dr-lozanov.dir.bg/book/start_book.htm $4 / 30 / 2006$

[4] Richards, J. C. and Rodgers, T. S. (2001). Approaches and Methods in Language Teaching (2nd ed.). Cambridge: Cambridge University Press.

[5] Felix, Uschi (1989). An Investigation of the Effects of Music, Relaxation and Suggestion in Second Language Acquisition in Schools. Flinders University, Adelaide. Chapter 2.7. Retrieved January 12, 2012.

[6] Schiffler, Ludger: "Suggestopedic Methods and Applications", Philadelphia, Tokyo, Paris: Gordon \& Breach Science Publisher, 1992.

[7] Schiffler, Ludger, Interhemispheric Foreign Language Learning - Activating Both Sides of the Brain, online 2003 (732KB) (download available: http://www.ludger-schiffler.de).

[8] Sergio, Paulo, Accelerating the Foreign Language Teaching Through Suggestopedia/Neuropedia, online 2010 (download available: http://www.lozanov.com.br

[9] Piaget, J. (1926). The Language and Thought of the Child. London: Routledge \& Kegan.

[10] Piaget, J. (1975/1936). "La Naissance de L'intelligence Chez L'enfant". ["Emergence of Intelligence in the Child"]. Neuchatel: Delachaux et Niesl. Cited in Tomic, W. \& Kingma, J (1996). Three Theories of Cognitive Representation and Their Evaluation Standards of Training Effect. Heerlson, The Netherlands: The Open University.

[11] Piaget, J (1975/1936). "La Naissance de L'intelligence Chez L'enfant". ["Emergence of Intelligence in the Child"] in Three Theories of Cognitive Representation and Their Evaluation Standards of Training Effect. Neuchatel: Delachaux et Niesl Heerlson.

[12] Johann Karl Friedrich Rosenkranz (1848) Pedagogics as a System. Translated 1872 by Anna C. Brackett, R. P. Studley Company.

[13] Johann Karl Friedrich Rosenkranz (1899). The philosophy of education. D. Appleton and Co.

[14] Vygotsky, D. (1962). Thought and Language. Cambridge, MA: MIT Press. 